\title{
Global transcriptomic profiles of circulating leucocytes in early lactation cows with clinical or subclinical mastitis
}

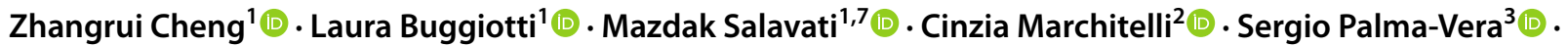

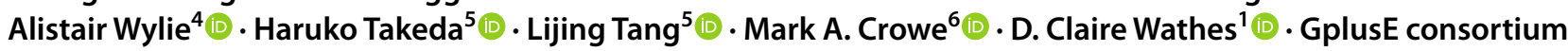

Received: 17 January 2021 / Accepted: 11 June 2021

(C) The Author(s), under exclusive licence to Springer Nature B.V. 2021

\begin{abstract}
Bovine mastitis, an inflammatory disease of the mammary gland, is classified as subclinical or clinical. Circulating neutrophils are recruited to the udder to combat infection. We compared the transcriptomic profiles in circulating leukocytes between healthy cows and those with naturally occurring subclinical or clinical mastitis. Holstein Friesian dairy cows from six farms in EU countries were recruited. Based on milk somatic cell count and clinical records, cows were classified as healthy $(n=147)$, subclinically $(n=45)$ or clinically mastitic $(n=22)$. Circulating leukocyte RNA was sequenced with Illumina NextSeq single end reads (30 M). Differentially expressed genes (DEGs) between the groups were identified using CLC Genomics Workbench V21, followed by GO enrichment analysis. Both subclinical and clinical mastitis caused significant changes in the leukocyte transcriptome, with more intensive changes attributed to clinical mastitis. We detected 769 DEGs between clinical and healthy groups, 258 DEGs between subclinical and healthy groups and 193 DEGs between clinical and subclinical groups. Most DEGs were associated with cell killing and immune processes. Many upregulated DEGs in clinical mastitis encoded antimicrobial peptides (AZU1, BCL3, CAMP, CATHL1, CATHL2, CATHL4,CATHL5, CATHL6, CCL1, CXCL2, CXCL13, DEFB1, DEFB10, DEFB4A, DEFB7, LCN2, PGLYRP1, PRTN3, PTX3, S100A8, S100A9, S100A12, $S L C 11 A 1, T F$ and $L T F$ ) which were not upregulated in subclinical mastitis. The use of transcriptomic profiles has identified a much greater up-regulation of genes encoding antimicrobial peptides in circulating leukocytes of cows with naturally occurring clinical compared with subclinical mastitis. These could play a key role in combatting disease organisms.
\end{abstract}

Keywords Bovine mastitis $\cdot$ Inflammation $\cdot$ Next generation sequence $\cdot$ Transcriptome

$\begin{array}{ll}\text { Abbreviations } \\ \text { AMP } & \text { Antimicrobial peptide } \\ \text { BH } & \text { Benjamini Hochberg } \\ \text { DEG } & \text { Differentially expressed gene } \\ \text { DIM } & \text { Days in milk } \\ \text { GO } & \text { Gene ontology }\end{array}$

The members of GplusE Consortium are listed in Acknowledgements section.

$\begin{array}{ll}\text { LDH } & \text { Lactate dehydrogenase } \\ \text { NAGase } & N \text {-acetyl- } \beta \text {-D-glucosaminidase } \\ \text { PAMP } & \text { Pathogen-associated molecular pattern } \\ \text { PMNL } & \text { Polymorphonuclear leukocytes } \\ \text { SC } & \text { Somatic cells } \\ \text { SCC } & \text { Somatic cell count }\end{array}$

4 Agri-Food and Biosciences Institute, Newforge Lane, Upper Malone Road, Belfast BT9 5PX, UK

5 Unit of Animal Genomics, GIGA Institute, University of Liège, Liège, Belgium

6 School of Veterinary Medicine, University College Dublin, Dublin 4, Ireland

7 Present Address: The Roslin Institute, Royal (Dick) School of Veterinary Studies, Easter Bush Campus, Midlothian, UK 


\section{Introduction}

Bovine mastitis is an inflammatory disease of the mammary gland. Clinical mastitis has easily recognisable symptoms. The most obvious is udder inflammation, with redness, swelling and heat around the affected area. There are visible changes in milk appearance and quality associated with a high milk somatic cell count (SCC). Mastitis can be caused by metabolic disorders, by tissue trauma and, most commonly, by environmental or contagious pathogenic microorganisms [1,2]. Causative agents are mainly bacteria but may also include fungi, yeasts and viruses. The annual costs to the dairy industry of dealing with mastitis have been estimated at over $\$ 2$ billion per annum in both Europe and the USA [3, 4]. There have been huge investments over many years into the development of new strategies for the prevention, diagnosis and management of mastitis, but it nevertheless remains the most economically significant bacterial disease of dairy cattle worldwide [2]. Continued advances in mastitis control are therefore necessary to ensure sustainability of dairy farming.

The most common pathogenic organisms causing bovine mastitis include Escherichia coli, Streptococcus uberis and Staphylococcus aureus [5-7]. In recent years the bacteriological aetiology has changed from primarily contagious forms (such as $S$. aureus) to environmental pathogens (such as E. coli and S. uberis) [8]. These bacteria enter the mammary gland and are recognised by the interaction of their pathogen-associated molecular patterns (PAMP) with Toll-like receptors (TLR2 and TLR4) expressed in resident macrophages and epithelial cells. This leads to a cascade of inflammatory responses, including the recruitment of inflammatory cells (predominantly circulating leukocytes) and upregulation of inflammatory mediators $[9,10]$. The resulting inflammation causes tissue damage within the udder and the associated shedding of somatic cells (SC) into the milk. Milk SC consist of many cell types, including epithelial cells, macrophages, polymorphonuclear leukocytes and lymphocytes. Both the amount of SC and changes in their gene expression are associated with physiological and pathological processes in the mammary gland. Numerous studies have found that an increase in SCC is associated with the presence of bacterial infection and this has been widely used in the diagnosis of bovine mastitis [11]. Cows with a healthy udder have a SCC $<100,000$ cells $/ \mathrm{ml}$ milk [2]. When the SCC is greater than this, mastitis is possible. A SCC $>400,000$ cells $/ \mathrm{ml}$ of milk is deemed to be unfit for human consumption (EEC directive 92/46).

The development of intra-mammary inflammation activates signalling pathways involving common and hepatic-specific transcription factors and pro-inflammatory mediators, which in turn leads to differential expression of acute phase proteins, complement components, chemokines, antimicrobial peptides (AMPs) and cell adhesion molecules [12-14]. Circulating leukocytes are then recruited to the inflamed mammary gland via a series of mechanisms, such as chemokine ligand-mediated cell migration and adhesion [15]. An assessment of the common genes upregulated in response to experimental infections with either $E$. coli or $S$. uberis concluded that the main signalling pathways activated were: (1) granulocyte adhesion and diapedesis, (2) ephrin receptor signalling, (3) RhoA signalling and (4) LPS/IL1 mediated inhibition of RXR function [16]. In order to achieve an appropriate balance between pathogen elimination and excessive tissue damage, then it is important that the movement of leukocytes into the mammary gland occurs in a timely fashion and is properly controlled [17].

A high proportion of dairy cows undergo various infections of their reproductive system, such as endometritis/ metritis and mastitis $[18,19]$ due to suppressed immune function during early lactation. This immunosuppression includes a reduction in the number of circulating leukocytes $[20,21]$ and their functional capacity [22, 23]. Moreover, polymorphonuclear leukocytes (PMNL) exhibit impaired phagocytic and oxidative activity $[22,24]$ and a reduction of both cellular and humoral immunities was observed, in which the responsiveness of circulating $\mathrm{T}$ cells to mitogenic agents and production of immunoglobulin by B cells were decreased [25, 26].

Circulating leukocytes therefore play crucial roles in the initiation, development and resolution of mastitis as they are the major source of immune cells attracted to the mammary gland during an infection. Most previous studies of the leukocyte inflammatory responses during mastitis have used experimentally developed models of clinical mastitis $[3,27,28]$. Less information is available concerning subclinical mastitis or naturally occurring disease. The present study investigated cows with naturally occurring subclinical or clinical mastitis in early lactation identified on six unrelated farms. Changes in global transcriptomic gene expression were determined using next-generation RNA sequencing and bioinformatics approaches. This has enabled us to compare the differing systemic responses associated with the two forms of this important disease.

\section{Materials and methods}

\section{Animals and sample collection}

Holstein Friesian cows for circulating leukocyte RNA sequencing were sampled as part of GplusE, a multinational 
research consortium FP7 project (http://www.gpluse.eu/). All sampling and diagnostic methods were performed according to standard operation procedures agreed within the consortium [29, 30]. Cows were recruited from six dairy farms located in the UK (Agri-Food and Biosciences Institute Hillsborough, Northern Ireland), Denmark (Aarhus University), Ireland (University College Dublin), Germany (Leibniz Institute for Farm Animal Biology), Belgium (Walloon Agricultural Centre) and Italy (Consiglio per la Ricerca in Agricoltura e l'Analsi dell'Economia Agraria). More details are given in Supplementary file 1 (1.1). All procedures had local ethical approval and complied with the relevant national and EU legislation under European Union Directive 2010/63/EU. Details of the nutritional management of each herd and the milk yields by herd over the first 50 DIM were provided previously [30]. For all cows in the study, milk yield over the initial 7 -week period averaged $33.3 \pm 9.3 \mathrm{~kg} /$ day. A summary of the milk composition data by herd is provided in Supplementary file 2 .

All cows were milked twice daily, and milk yields were recorded from approximately 3 days in milk (DIM) onwards. Milk samples were collected from consecutive morning and evening milkings twice weekly between seven to 49 DIM, stored at $4{ }^{\circ} \mathrm{C}$ and subsequently analysed for composition of protein, fat and lactose and for SCC through milk quality testing. Clinical mastitis was diagnosed using standard methods based on daily observations for abnormal changes in milk appearance (e.g. flakes, clots), quality, milk yield and mammary inflammatory responses (redness, swelling, heat, or pain). Additional morning milk samples (two $\times 8 \mathrm{ml}$ ) were collected twice weekly and stored at $-18^{\circ} \mathrm{C}$. The enzymes lactate dehydrogenase (LDH) (EC. 1.1.1.27) and $N$-acetyl$\beta$-D-glucosaminidase (NAGase) (EC 3.2.1.30) were analysed by fluorometric assays [31]. Raised concentrations of both enzymes are indicators of mastitis [31].

Blood samples were collected by jugular venepuncture from a total of 214 multiparous cows from the six herds at $14 \pm 4$ DIM into Tempus ${ }^{\mathrm{TM}}$ blood RNA tubes (Thermo Fischer Scientific, Loughborough, UK) using a standard protocol. The Tempus tubes were shaken vigorously for 15-20 s immediately upon collection, then frozen and stored at $-80{ }^{\circ} \mathrm{C}$ for RNA extraction. The milk SCC readings obtained in week 2 of lactation from the day nearest to the blood sample collection ( \pm 2 days) and the clinical diagnoses provided by the farms were subsequently used to categorize the cows into three groups at the time when the RNAseq analysis was performed. Healthy cows were defined as having a SCC $<100,000$ cells $/ \mathrm{ml}$ milk and no clinical symptoms $(\mathrm{n}=147)$. Sub-clinically mastitic cows were defined as having a SCC between 100,000 and 400,000 cells $/ \mathrm{ml}$ milk and no apparent clinical symptoms $(\mathrm{n}=45)$. Cows diagnosed as having clinical mastitis had a SCC $>400,000$ cells $/ \mathrm{ml} \mathrm{milk}$ and showed some of the above clinical symptoms $(n=22)$.

\section{RNA extraction}

Total RNA from whole blood samples collected in Tempus tubes was extracted using Tempus spin isolation kits (Thermo Fisher Scientific) following the supplied protocol. RNA quantity and integrity were assessed using an Agilent BioAnalyzer 2000 (Agilent, Cheshire, UK) and Agilent RNA 6000 Nano Kit. RNA quantity and purity were also validated using a DeNovix DS-11 spectrophotometer (Cambridge Bioscience, UK). All selected RNA sample had a reasonable integrity (RIN number $>7$ ) and purity (260/280 between 1.8 and 2.3). Quality data are summarised in Supplementary file 3 . The RNA was kept at $-80{ }^{\circ} \mathrm{C}$ for subsequent RNA-Sequencing.

\section{RNA-sequencing, mapping and quantification}

RNA-seq libraries were prepared from $750 \mathrm{ng}$ of whole blood total RNA with the Illumina TruSeq Stranded Total RNA Library Prep Ribo-Zero Gold kit (Illumina, San Diego, California, USA) using the epMotion liquid handling workstation (Eppendorf, Hamburg, Germany). Pooled cDNA libraries were sequenced on the Illumina NextSeq 500 sequencer at 75 nucleotide length single end reads to reach an average of 30 million reads per sample. FASTQ files were deposited to the European Nucleotide Archive (ERP019874).

A CLC Genomics Workbench V21 (Qiagen Digital Insights, Redwood City, CA 94063, USA) was used for sequencing analysis based on its built-in workflows, including trimming the poor quality reads, quality control and mapping the reads to a reference genome of Bos taurus assembly (ARS-UCD1.2) and quantifying reads per gene.

\section{Statistical analysis}

The differentially expressed genes (DEG) between the groups were identified with a toolbox of Differential Expression for RNA-Seq built in CLC Genomics Workbench V21. This included trimmed mean and Z-score normalizations across all samples and a statistics based on a negative binomial generalized linear model, in which mastitic group was set as test variable and herd as confounding variable to control the differences of gene expression arising from herds. The genes with an absolute fold change $\geq 1.25$ in pairwise comparisons between the three groups (Healthy, clinical mastitis and subclinical mastitis) were selected for subsequent analysis. P-values for the genes were adjusted using the Benjamini-Hochberg $(\mathrm{BH})$ procedure and significance was considered at $\mathrm{P}<0.05$. The DEGs identified as significant in blood leucocytes were uploaded into Partek Genomics Suite (Partek Incorporation, Missouri, USA) for GO enrichment analysis focussing on Biological Processes 
with a genome version of ARS-UCD1.2 to investigate the biological functions and interactions between genes and pathways. Fisher's exact test with BH adjustment was used and statistical significance was considered at $P<0.05$.

\section{Results}

The cows were classified as healthy, subclinically mastitic or clinically mastitic. The corresponding SCC values were $38,000 \pm 21,400(n=147), 194,000 \pm 80,400(n=45)$ and $2,137,000 \pm 2,144,100(\mathrm{n}=22)$ cells $/ \mathrm{ml}$ milk respectively $($ mean $\pm \mathrm{SD})$. The values remained in the same ranges by group at weeks 3 and 5 (Supplementary file $1(1.2)$ ). The milk enzyme LDH was significantly higher at the time of blood sample collection (week 2) in the cows with clinical mastitis compared with the healthy cows or those with subclinical mastitis $(\mathrm{P}<0.0001)$ while NAGase showed a progressive increase healthy $<$ subclinical $<$ clinical $(\mathrm{P}<0.05-0.0001$, Supplementary file 4$)$. The mean lactation numbers did not differ between groups (healthy, $2.58 \pm 1.25$, sub-clinical, $2.71 \pm 1.75$, clinical, $2.91 \pm 1.69$, mean $\pm S D$, Supplementary file $1(1.1)$ ). Metritis was recorded in 17/147 (11.6\%) healthy cows, $3 / 45$ (6.7\%) subclinical mastitis cows and 3/21 (14.3\%) clinical mastitis cows. A breakdown of the mastitis classifications by herd is also given in Supplementary file 1 (1.1), showing that infected animals were distributed across all 6 herds. A Venn diagram showing the differentially expressed genes (DEGs) in each group and their overlap is given in Supplementary file 5.

\section{Comparison between the healthy cows and those with clinical mastitis}

Firstly, we compared the global transcriptomic gene expression in leukocytes between healthy cows and those with clinical mastitis. This identified 769 DEGs after BH adjustment for multiple tests (listed in Supplementary file 6), of which 377 were upregulated and 392 downregulated in the cows with clinical mastitis compared with the healthy cows. The top 20 upregulated and downregulated DEGs are given in Table 1. This demonstrated that various types of AMPs were upregulated by over three fold in the cows with clinical mastitis, including PTX3, CATHL2, CATHL5, CATHL6, CAMP, AZU1, TF, LTF, PGLYRP1 and PRIN3. Of these, the greatest fold change of 64 related to PTX3. Eight out of the 20 top upregulated genes are involved in immune/ inflammatory process, including VEPH1, HSPA6, CRISP3, STEAP1, EREG, MMP8, CD177 and TNFAIP6. The top 20 downregulated genes are involved in various functions without clear themes. For example, five are involved in protein binding activity (DES, SEMA6B, CNN1, TAGLN and $A A R S D 1$ ), of which DES and SEMA6B were decreased by 31 and 6.2 fold, respectively. The remainder had fold changes
Table 1 Top 20 upregulated and downregulated circulating leukocyte genes between the healthy (control) cows $(n=147)$ and those with clinical mastitis $(\mathrm{n}=22)$

\begin{tabular}{|c|c|c|c|c|c|}
\hline \multicolumn{3}{|c|}{ Upregulated genes } & \multicolumn{3}{|c|}{ Downregulated genes } \\
\hline Gene symbol & Fold change & $\mathrm{P}^{*}$ & Gene symbol & Fold change & $\mathrm{P}^{*}$ \\
\hline$P T X 3$ & 63.82 & $4.42 \mathrm{E}-42$ & $D E S$ & -30.91 & $5.63 \mathrm{E}-06$ \\
\hline VEPHI & 22.13 & $2.12 \mathrm{E}-21$ & SEMA6B & -6.23 & $2.14 \mathrm{E}-03$ \\
\hline HSPA6 & 8.47 & $7.23 \mathrm{E}-34$ & CNN1 & -4.17 & $1.20 \mathrm{E}-02$ \\
\hline CATHL6 & 8.26 & $3.10 \mathrm{E}-07$ & TAFA4 & -3.67 & $2.15 \mathrm{E}-03$ \\
\hline$A Z U 1$ & 6.57 & $5.78 \mathrm{E}-06$ & LYNX1 & -3.52 & $5.87 \mathrm{E}-03$ \\
\hline CATHL2 & 6.12 & $1.36 \mathrm{E}-06$ & $T A G L N$ & -2.88 & $7.86 \mathrm{E}-03$ \\
\hline$L T F$ & 5.03 & $3.46 \mathrm{E}-08$ & MBOAT2 & -2.62 & $1.40 \mathrm{E}-03$ \\
\hline CRISP3 & 5.02 & $2.72 \mathrm{E}-05$ & GIMD1 & -2.41 & $5.86 \mathrm{E}-03$ \\
\hline STEAP1 & 4.81 & $8.45 \mathrm{E}-07$ & CST8 & -2.34 & $2.93 \mathrm{E}-02$ \\
\hline EREG & 4.26 & $5.85 \mathrm{E}-06$ & WDR74 & -2.32 & $2.54 \mathrm{E}-04$ \\
\hline$M M P 8$ & 4.16 & $9.55 \mathrm{E}-07$ & ANGPTL3 & -2.10 & $1.26 \mathrm{E}-02$ \\
\hline CAMP & 3.91 & $8.66 \mathrm{E}-05$ & GLT8D2 & -1.98 & $1.21 \mathrm{E}-03$ \\
\hline PRTN3 & 3.83 & $7.43 \mathrm{E}-06$ & $S L C 25 A 21$ & -1.97 & $2.07 \mathrm{E}-02$ \\
\hline$A L B$ & 3.81 & $2.83 \mathrm{E}-02$ & C12H13orf46 & -1.96 & $1.12 \mathrm{E}-02$ \\
\hline PGLYRP1 & 3.52 & $1.02 \mathrm{E}-06$ & ADAM32 & -1.96 & $1.64 \mathrm{E}-03$ \\
\hline$T F$ & 3.34 & $3.48 \mathrm{E}-02$ & SMIM18 & -1.95 & $3.24 \mathrm{E}-03$ \\
\hline CATHL5 & 3.17 & $9.28 \mathrm{E}-04$ & $A A R S D 1$ & -1.92 & $2.11 \mathrm{E}-02$ \\
\hline MYRFL & 3.15 & $1.49 \mathrm{E}-06$ & $L Y 6 D$ & -1.89 & $9.44 \mathrm{E}-03$ \\
\hline$C D 177$ & 3.12 & $3.56 \mathrm{E}-05$ & TMEM232 & -1.88 & $9.23 \mathrm{E}-04$ \\
\hline TNFAIP6 & 3.11 & $1.96 \mathrm{E}-07$ & $S L C 22 A 7$ & -1.87 & $3.52 \mathrm{E}-03$ \\
\hline
\end{tabular}

*P values were adjusted using the Benjamini-Hochberg method for false discovery rate control 
between 1.9 and 4.2 and included four involved in immunity/inflammation (TAFA4, LYNX1, LY6D and TMEM18) and four involved in metabolism (MBAOT2, ANGPTL3, GLT8D2 and SLC22A7).

The upregulated and downregulated DEGs were separately subjected to GO enrichment analysis to identify the functional groups and pathways. For the upregulated DEGs, over 1000 biological functions were significantly enriched. The top GO functions were: (1) interspecies interaction between organisms, with 44 DEGs involved in body defence and killing other organisms; (2) immune system process, with 46 DEGs involved in various immune processes (immune response, leukocyte migration, immune effector process and activation of immune response, etc.) and (3)
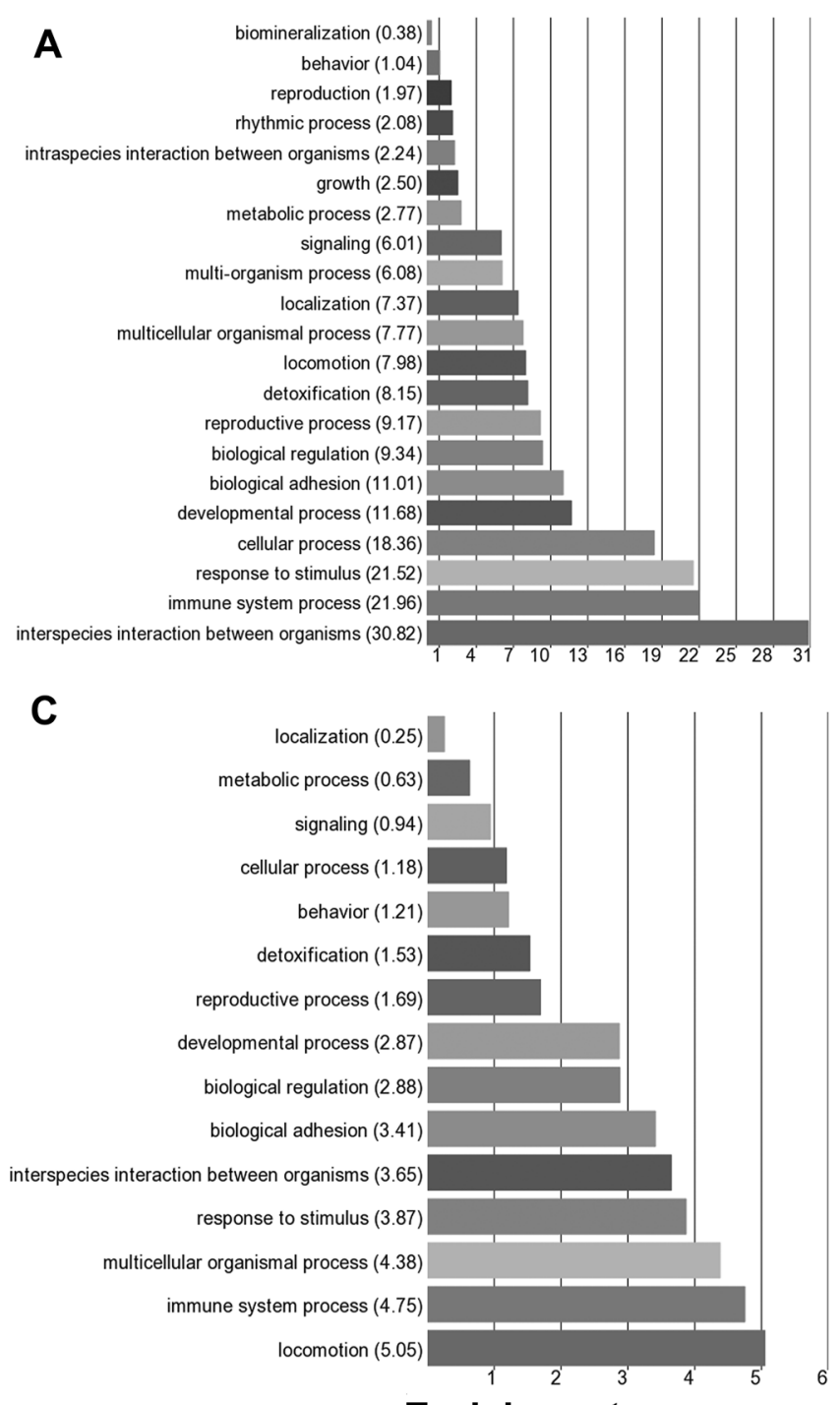

Enrichment score

Fig. 1 Gene Ontology (GO) enrichment analysis for the differentially expressed leukocyte genes which were upregulated (A) or downregulated $(\mathbf{B})$ between the cows with clinical mastitis $(n=22)$ and the response to stimulus, with 122 DEGs involved in antimicrobial and immune activities (Fig. 1A, Table 2). For the downregulated DEGs, many fewer biological functions (218) were identified and the enrichment scores were smaller compared with those of the upregulated DEGs (Fig. 1B). The top biological functions were multicellular organism process (49 DEGs), localisation (66 DEGs) and signalling (7 DEGs).

\section{Comparison between the healthy cows and those with subclinical mastitis}

The analysis identified 258 DEG between the healthy cows and those with subclinical mastitis (Supplementary file 7), most of which (198) were downregulated in subclinically

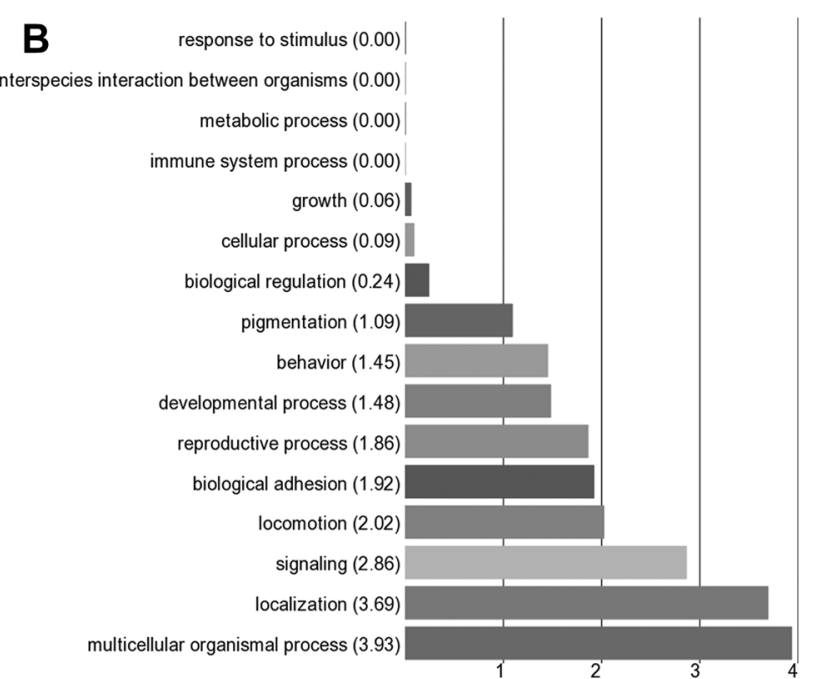

D

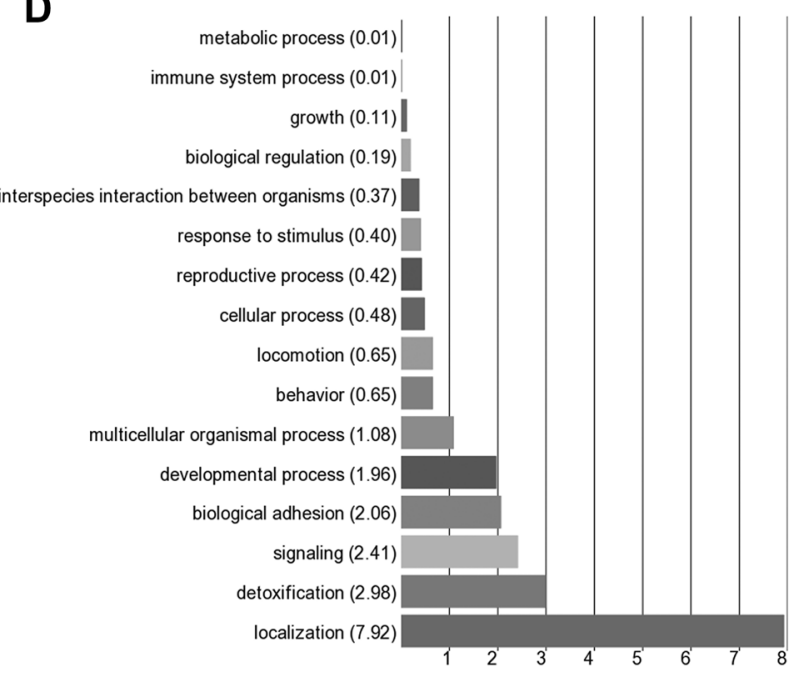

\section{Enrichment score}

healthy cows $(n=147)$, and upregulated $(\mathbf{C})$ or downregulated (D) between the cows with subclinical mastitis $(n=45)$ and the healthy cows $(n=144)$ 
Table 2 Summary of GO enrichment main functions of DEGs upregulated in the cows with clinical mastitis compared with the healthy cows or those with subclinical mastitis

\begin{tabular}{|c|c|c|}
\hline Function & $\begin{array}{l}\text { Enrich- } \\
\text { ment } \\
\text { score }\end{array}$ & DEGs in the function \\
\hline \multicolumn{3}{|l|}{ Clinical mastitis vs healthy cows } \\
\hline Interspecies interaction between organisms & 31 & $\begin{array}{l}\text { PTX3, CATHL6, AZU1, LTF, PGLYRP1, TF, CXCL13, LRG1, CATHL1, CATHL4, } \\
\text { LCN2, S100A9, APOA2, HP, DEFB1, CD14, S100A8, CCL8, CFB, GZMA, } \\
\text { S100A12, FCGR1A, RSAD2, NECTIN2, ARG2, MX2, IL18,IL12B, FKBP5, } \\
\text { SLC11A1, BCL3, RGS1, HMGB3, CSF1, CEBPE, TMEM229B, CFP, FAM20A, } \\
\text { SCARB1, STOM, CEBPB, PYCARD, ANXA1, MX1 }\end{array}$ \\
\hline Immune system process & 22 & $\begin{array}{l}\text { PTX3, AZU1, LTF, PRTN3, PGLYRP1, THY1, CXCL13, LCN2, VTN, DCSTAMP, } \\
\text { S100A9, CDH26, HP, ADGRG3, CD14, S100A8, ITGA9, IL18R1, CFB, ALOX5, } \\
\text { S100A12, EGR1, FCGR1A, IL18RAP, RSAD2, CD24, ARG2, MX2, IL18, IL2RA, } \\
\text { IL12B, PTPRO, SLC11A1, BCL3, HMGB3, CSF1, LGALS9, MERTK, HSD3B7, } \\
\text { CFP, PYCARD, LTBR, ANXA1, SKAP2, STAT3, MX1 }\end{array}$ \\
\hline Response to stimulus & 22 & $\begin{array}{l}\text { PTX3, HSPA6, CATHL6, AZU1, LTF, ALB, PGLYRP1, TF, MMP9, CXCL13, LRG1, } \\
\text { CATHL1, CATHL4, ALPL, FOLR3, CREB3L3, LCN2, VTN, GLP1R, RAB20, } \\
\text { TBX3, TNIP3, DCSTAMP, HSPA1A, S100A9, AREG, APOA2, ORM1, CD163, HP, } \\
\text { SLC6A2, RYR1, DEFB1, CD14, S100A8, DYSF, CFB, ALOX5, NMUR2, GZMA, } \\
\text { S100A12, EGR1, GRPR, SOD2, SOCS1, FCGR1A, IL18RAP, RSAD2, CHI3L1, } \\
\text { P2RX1, TREM1, CAPN3, SOCS3, ETV5, PLA2G4F, CDKN1A, SORT1, MFSD2A, } \\
\text { GCH1, WIPI1, CD24, AK4, ROR2, ARG2, NUPR1, FOSB, MT2A, AURKB, } \\
\text { UHRF1, GPBAR1, PAX8, MX2, IL18, MAPK13, IL12B, FKBP5, ACVR1C, MGST1, } \\
\text { SLC11A1, BCL3, MSC, RGS1, HMGB3, CSF1, CEBPE, MANF, PRDX5, BAG3, } \\
\text { PAM, PTAFR, TMEM229B, CFP, CADPS2, PYCR1, FAM20A, FOS, HSPA5, } \\
\text { MYBL2, DTL, SCARB1, HK2, TFEC, SESN2, DNAJB1, METRNL, NIBAN1, } \\
\text { PLA2G4A, CEBPB, PYCARD, LTBR, ANXA1, GADD45A, STAT3, KLF4, FAIM2, } \\
\text { AQP9, MX1, FANCD2, PTTG1, CDC25A, MCM2, SDC4 }\end{array}$ \\
\hline \multicolumn{3}{|l|}{ Clinical mastitis vs subclinical mastitis } \\
\hline Interspecies interaction between organisms & 22 & $\begin{array}{l}\text { PTX3, CATHL6, CATHL4, AZU1, LTF, PGLYRP1, CATHL1, LCN2, LRG1, CXCL13, } \\
\text { DEFB1, S100A9, HP, S100A8, CD14, CFB, FCGR1A, S100A12, NECTIN2, } \\
\text { FAM20A, HSPB1, TMEM229B, RGS1, FKBP5 }\end{array}$ \\
\hline Response to stimulus & 13 & $\begin{array}{l}\text { PTX3, CATHL6, HSPA6, CATHL4, AZU1, LTF, PGLYRP1, CATHL1, MMP9, ALPL, } \\
\text { CREB3L3, FOLR3, LCN2, LRG1, CXCL13, DEFB1, RAB20, PLOD2, HSPA1A, } \\
\text { TNIP3, S100A9, SLC6A2, HP, AREG, DYSF, RYR1, DCSTAMP, S10OA8, CD163, } \\
\text { EGR1, CD14, CFB, FCGR1A, S100A12, ETV5, IL18RAP, PAX8, FOSB, ROR2, } \\
\text { MAPK13, FOS, WIPI1, GPBAR1, CHI3L1, TREM1, CDKN1A, SOD2, GCH1, } \\
\text { FAM2OA, DNAJB1, PRDX5, NAPRT, HSPB1,TMEM229B, RGS1, FKBP5, TFEC }\end{array}$ \\
\hline Immune system process & 11 & $\begin{array}{l}\text { PTX3, AZU1, LTF, PGLYRP1, PRTN3, THY1, LCN2, CXCL13, S100A9, HP, IL18R1, } \\
\text { DCSTAMP, ADGRG3, S100A8, EGR1, CD14, CFB, FCGR1A, S100A12, IL18RAP, } \\
\text { IL2RA }\end{array}$ \\
\hline
\end{tabular}

mastitic cows, with only 60 DEGs upregulated. The top 20 upregulated and downregulated DEGs are presented in Table 3. GO enrichment analysis showed that the upregulated DEGs play significant roles in 352 biological functions (Fig. 1C). The top five enriched functions were: (1) locomotion (CCL26, ALOX5, EDNRB, ADTRP, GFRA3 and ADAMTS12); (2) immune system process (CCL26, FGA, AICDA, ALOX5, EDNRB, MX2 and RSAD2; (3) multicellular organismal process $(M Y H 2, T B X 3, A C T A 1$, CHRM3, NMUR2, ALOX5, SLC7A11, ADGRG1, EDNRB, TGM3 and CCDC151); (4) response to stimulus (17 DEGs) and (5) interspecies interaction between organisms ( $F G A$, AICDA, MX2, RSAD2 and GZMA). The downregulated
DEGs were involved in 257 biological functions and the GO enrichment summary is demonstrated in Fig. 1D. The top five functions were: (1) localization (43 DEGs); (2) detoxification ( $H B A, H B M$ and $H B B)$; (3) signalling (4 DEGs); (4) biological adhesion (7 DEGs) and (5) developmental process (34 DEGs). Among the 43 downregulated DEGs in the "localization" function, 12 were solute carriers (SLC16A2, SLC20A2, SLC22A7, SLC23A1, SLC24A1, SLC25A21, SLC38A11, SLC4A1, SLC4A3, SLC5A7, $S L C 9 A 3$ and $S L C 9 A 5)$. The "detoxification" function contained genes encoding three haemoglobin subunits ( $H B A$, $H B B$ and $H B M$ ). 
Table 3 Top 20 upregulated and downregulated circulating leukocyte genes between the healthy (control) cows $(n=147)$ and those with subclinical mastitis $(n=45)$

\begin{tabular}{|c|c|c|c|c|c|}
\hline \multicolumn{3}{|c|}{ Upregulated genes } & \multicolumn{3}{|c|}{ Downregulated genes } \\
\hline Gene symbol & Fold change & $\mathrm{P}^{*}$ & Gene symbol & Fold change & $\mathrm{P}^{*}$ \\
\hline MYH2 & 4.62 & $2.52 \mathrm{E}-03$ & SEMA6B & -14.79 & $9.54 \mathrm{E}-09$ \\
\hline ATP6VOC & 3.46 & $3.63 \mathrm{E}-05$ & TAFA4 & -3.50 & $2.03 \mathrm{E}-04$ \\
\hline THEG & 2.66 & $1.74 \mathrm{E}-02$ & CATHLA & -2.73 & $1.46 \mathrm{E}-02$ \\
\hline CCL26 & 2.60 & $2.87 \mathrm{E}-03$ & $D M T N$ & -2.71 & $7.98 \mathrm{E}-03$ \\
\hline$F G A$ & 2.53 & $3.45 \mathrm{E}-02$ & $H B A$ & -2.59 & $5.48 \mathrm{E}-03$ \\
\hline$T B X 3$ & 2.30 & $2.12 \mathrm{E}-04$ & $M A R C O$ & -2.56 & $1.25 \mathrm{E}-02$ \\
\hline PRG3_1 & 2.30 & $7.89 \mathrm{E}-03$ & $L Y N X 1$ & -2.18 & $1.77 \mathrm{E}-02$ \\
\hline RNASE2 & 2.04 & $1.45 \mathrm{E}-02$ & $H B M$ & -2.02 & $1.30 \mathrm{E}-02$ \\
\hline ACTAl & 1.92 & $2.06 \mathrm{E}-02$ & SLC4A1 & -1.96 & $7.40 \mathrm{E}-03$ \\
\hline$B D K R B 2$ & 1.86 & $1.91 \mathrm{E}-02$ & $A L A S 2$ & -1.94 & $9.04 \mathrm{E}-03$ \\
\hline PRG3_2 & 1.85 & $2.42 \mathrm{E}-02$ & C17orf100 & -1.91 & $2.26 \mathrm{E}-02$ \\
\hline$G Z M B \_2$ & 1.77 & $1.32 \mathrm{E}-02$ & $H B B$ & -1.89 & $1.42 \mathrm{E}-02$ \\
\hline GNG4 & 1.76 & $1.43 \mathrm{E}-02$ & $M S M B$ & -1.87 & $1.06 \mathrm{E}-02$ \\
\hline$H A L$ & 1.63 & $1.30 \mathrm{E}-03$ & $A Q P 1$ & -1.85 & $2.61 \mathrm{E}-02$ \\
\hline GPAT2 & 1.63 & $9.38 \mathrm{E}-03$ & C15H11orf94 & -1.84 & $8.09 \mathrm{E}-03$ \\
\hline OVOS2 & 1.63 & $9.20 \mathrm{E}-03$ & $A D D 2$ & -1.79 & $1.56 \mathrm{E}-02$ \\
\hline CDHR5 & 1.62 & $9.11 \mathrm{E}-03$ & $D H D H$ & -1.77 & $4.01 \mathrm{E}-03$ \\
\hline SERPINB10 & 1.53 & $1.91 \mathrm{E}-02$ & SPACA7 & -1.69 & $3.13 \mathrm{E}-02$ \\
\hline$A I C D A$ & 1.53 & $1.04 \mathrm{E}-02$ & SLC22A7 & -1.67 & $3.42 \mathrm{E}-03$ \\
\hline$H B E 2$ & 1.52 & $4.96 \mathrm{E}-02$ & ESRP1 & -1.62 & $4.87 \mathrm{E}-02$ \\
\hline
\end{tabular}

*P values were adjusted using the Benjamini-Hochberg method for false discovery rate control

\section{Comparison of cows with clinical and subclinical mastitis}

The analysis identified 193 DEGs between the cows with subclinical and clinical mastitis, among which 166 were upregulated and 27 downregulated when fold changes were calculated as clinical/subclinical mastitis (Supplementary file 8). In the top 20 upregulated DEGs (Table 4), there were 11 genes encoding various AMPs (PTX3, CATHL1, CATHL2, CATHL4, CATHL6, AZU1, CAMP, LTF, PGLYRP1, PRTN3 and DEFB10) and 8 DEGs associated with other immune/inflammatory processes (CRISP3, MMP8, NGP, CD177, VEPH1, HSPA6, STEAP3 and $E R E G)$. Of these, $P T X 3$ was again the most differentially expressed (FC 61.7). In the top 20 downregulated DEGs (Table 4), seven are associated with immune/inflammatory processes (ATP6VOC, BDKRB2, KIR3DS1, CXCL2, CD209, PIDI and WNT9A) and many others are associated with cellular homeostasis, such as protein binding (DES, MYH2, ACTA1, TAC3 and STMN3) and cellular development (THEG, RNF212B and ZFYVE28). Over 700 biological functions were identified for the upregulated DEGs using GO enrichment analysis. Among them, the top functions were (1) interspecies interaction between organisms with 24 DEGs associated with response to and killing of other organisms; (2) response to stimulus (57 DEGs); (3) immune system process (21 DEGs); (4) detoxification (6 DEGs) and (5) developmental process (42 DEGs) (Table 2, Supplementary file 9A). GO enrichment analysis detected 100 altered biological functions for the downregulated DEGs in which only developmental process (THEG, ACTA1, PIDAl, WDT74 and WNT9A) had an enrichment score over 1 (Supplementary file 9B).

\section{Comparison of the common DEGs between healthy cows and those with subclinical or clinical mastitis}

A Venn diagram (Supplementary file 5) for the three groups of cows showed that there were 100 DEGs in the comparisons of both the clinical and subclinical mastitis groups with the healthy group. Among these common DEGs, most of them (79) were downregulated in the mastitic cows and only 21 were upregulated (Supplementary file 10). There were 169 DEGs in the comparisons of both the subclinical mastitis and healthy groups with the clinical mastitis group, in which most of them were upregulated (153) and only 16 were downregulated in the cows with clinical mastitis. The upregulated DEGs included a large proportion of genes encoding various AMPs (such as AZU1, CAMP, CATHL1, CATHL2, CATHL4, CATHL5, CATHL6, CXCL13, DEFB1, DEFB10, DEFB4A, DEFB7, LCN2, LTF, PGLYRP1, PRTN3, PTX3, S100A8, S100A9 and S100A12) and molecules associated with immune/inflammatory processes (such as CD14, CD34, CD163, CD177, CFB, CRISP3, 
Table 4 Top 20 upregulated and downregulated circulating leukocyte genes between the cows with subclinical $(n=45)$ and clinical $(n=22)$ mastitis

\begin{tabular}{|c|c|c|c|c|c|}
\hline \multicolumn{3}{|c|}{ Upregulated genes } & \multicolumn{3}{|c|}{ Downregulated genes } \\
\hline Gene symbol & Fold change & $\mathrm{P}^{*}$ & Gene symbol & Fold change & $\mathrm{P}^{*}$ \\
\hline$P T X 3$ & 61.69 & $8.65 \mathrm{E}-32$ & $D E S$ & -20.41 & $5.75 \mathrm{E}-04$ \\
\hline VEPHI & 24.32 & $4.13 \mathrm{E}-17$ & MYH2 & -18.74 & $1.47 \mathrm{E}-04$ \\
\hline CATHL6 & 9.86 & $1.79 \mathrm{E}-06$ & THEG & -4.72 & $2.30 \mathrm{E}-02$ \\
\hline HSPA6 & 8.25 & $4.38 \mathrm{E}-25$ & ACTA1 & -3.73 & $6.55 \mathrm{E}-03$ \\
\hline CATHL2 & 7.14 & $6.60 \mathrm{E}-06$ & ATP6VOC & -2.52 & $4.34 \mathrm{E}-02$ \\
\hline CATHLA & 6.93 & $1.06 \mathrm{E}-03$ & $B D K R B 2$ & -2.45 & $4.17 \mathrm{E}-02$ \\
\hline STEAPl & 6.72 & $7.45 \mathrm{E}-07$ & KIR3DS1 & -2.20 & $8.69 \mathrm{E}-03$ \\
\hline$A Z U 1$ & 6.45 & $1.50 \mathrm{E}-04$ & PIDI & -2.17 & $3.01 \mathrm{E}-02$ \\
\hline$L T F$ & 6.20 & $5.36 \mathrm{E}-08$ & CXCL2 & -1.98 & $1.79 \mathrm{E}-02$ \\
\hline CRISP3 & 6.20 & $4.98 \mathrm{E}-05$ & $T A C 3$ & -1.93 & $2.07 \mathrm{E}-02$ \\
\hline CAMP & 5.36 & $5.62 \mathrm{E}-05$ & WDR74 & -1.86 & $2.72 \mathrm{E}-02$ \\
\hline MMP8 & 4.98 & $1.91 \mathrm{E}-06$ & $C D 209$ & -1.85 & $2.20 \mathrm{E}-02$ \\
\hline PGLYRP1 & 4.84 & $8.19 \mathrm{E}-08$ & $R N F 212 B$ & -1.84 & $4.01 \mathrm{E}-02$ \\
\hline$C D 177$ & 4.58 & $2.12 \mathrm{E}-06$ & TMEM232 & -1.70 & $2.07 \mathrm{E}-02$ \\
\hline$N G P$ & 4.10 & $5.17 \mathrm{E}-05$ & NRIP3 & -1.63 & $2.70 \mathrm{E}-02$ \\
\hline $\mathrm{CCN} 3$ & 4.03 & $2.08 \mathrm{E}-02$ & ZFYVE28 & -1.62 & $4.74 \mathrm{E}-02$ \\
\hline$E R E G$ & 3.42 & $1.18 \mathrm{E}-03$ & $I D O 2$ & -1.60 & $3.41 \mathrm{E}-02$ \\
\hline CATHL1 & 3.40 & $7.75 \mathrm{E}-04$ & WNT9A & -1.53 & $4.03 \mathrm{E}-02$ \\
\hline PRTN3 & 3.39 & $1.14 \mathrm{E}-03$ & STMN3 & -1.47 & $3.42 \mathrm{E}-02$ \\
\hline DEFB10 & 3.36 & $3.28 \mathrm{E}-07$ & UCHL3 & -1.44 & $2.14 \mathrm{E}-03$ \\
\hline
\end{tabular}

*P values were adjusted using the Benjamini-Hochberg method for false discovery rate control
ERG1, MMP8, MMP9, VEPH1) (Supplementary file 11). Of these, $C D 14$ and $C D 163$ are commonly used markers for monocytes/macrophages, and MMP8, MMP9 and CD177 are markers for neutrophils. There were only two common DEGs (CATHL4 and GCA) shown in all three comparison pairs.

\section{Discussion}

Bovine mastitis is a significant problem for the dairy industry, resulting in both reduced milk quality and yield. This multifactorial disease is complex in origin, as many factors contribute to the development of mastitis, including different microbial species, and key aspects of the management and environment, particularly with relation to dry cow therapy, hygiene and housing [32]. Individual cows also exhibit varying degrees of susceptibility and resistance [24, 33]. In response to mastitis, the SCC increases due to the influx of immune cells, along with an inflammatory process. Previous studies have investigated circulating leukocyte gene expression in cows with mastitis induced by experimental infection with E. coli [27, 34] or S. aureus [35], but information on leukocyte gene expression profiles in cows with naturally occurring subclinical mastitis is lacking. Subclinical mastitis is, however, considered as the most economically important type of mastitis due to its higher prevalence and longer term effects $[2,36]$. Whole peripheral blood has previously been widely used in gene expression studies used to investigate disease due to its initial ease of collection and because it can be processed directly without the requirement to separate out specific cell types. The transcriptional changes measured between different cows in the study therefore represent changes in gene expression within particular cell types (which will include $\mathrm{T}$ and $\mathrm{B}$ lymphocytes, natural killer cells, platelets, PBMC and granulocytes (neutrophils, eosinophils and, basophils)) combined with alterations in their relative proportions [37]. Despite this limitation, transcriptional signatures of whole blood can reliably differentiate individuals with a variety of infections (e.g. human tuberculosis [38]). The present study demonstrated both the shared and different gene expression profiles in circulating leukocytes between cows with naturally occurring clinical or subclinical mastitis using next generation sequencing and bioinformatics approaches.

\section{Inflammation and immune defence mechanisms}

Invasion of pathogenic microorganisms into the mammary gland triggers inflammation and leads to the development of subclinical or clinical mastitis. These two types are interdependent. The initial stage of bovine mastitis may be subclinical which can subside, persist as a chronic inflammation or develop into a clinical inflammation [2]. Circulating 
leukocytes, as a major source of immune/inflammatory cells and body defence mechanisms, play crucial roles in initiation, maintenance and resolution of all types of mastitis [3, 39]. In the present study, we identified 258 DEGs in circulating leukocytes isolated from cows with subclinical mastitis and 769 DEGs from cows with clinical mastitis compared with the healthy cows. This suggests that the number of DEGs by circulating leukocytes was associated with the severity and development of the inflammatory process in the udder. The differences may also reflect the particular disease causing organism involved, but this was not possible to evaluate within the present experiment.

Clinical mastitis upregulated various biological functions related to responding, inhibiting and killing the invaded pathogens. Both the top 20 upregulated genes and top activated biological processes concentrated on the genes encoding various AMPs and immune/inflammatory molecules, with a clear theme of body defence against pathogen invasion. The GO enrichment scores of biological functions related to this theme were relatively high (31-22 for the top three functions). The function of interspecies interaction between organisms (mainly involved in responding to and killing invaded pathogens) had an enrichment score of 31 and comprised 44 upregulated genes. In contrast, the top 20 upregulated genes in the subclinical mastitis group had diverse functions, such as signalling (MYH2), reproductive (TBX3), oxidant detoxification (HBE2) and immune processes (CCL26, PGA, PRG3_1, PRG3_2, GZMB_2, RNASE2, BDKRB2, SERPINB10 and AIDA). The enrichment scores were also relatively low, in which the top five functions related to body defence scored at between 4 and 5 . The function of interspecies interaction between organisms and immune system process also had a relatively low enrichment score (4) and fewer players (5 and 7 DEGs, respectively). This indicates that the immune defence mechanisms activated in circulating leukocytes in the cows with clinical mastitis were more intensive than in those with subclinical mastitis.

Comparisons of the gene expression between the cows with clinical and subclinical mastitis identified 193 DEGs, in which 166 were upregulated in the clinically mastitic cows. Some of the genes might already be altered/upregulated in cows with subclinical mastitis and this may explain why fewer DEGs were detected in this comparison. The top 20 upregulated DEGs showed a clear theme of body immune defence against the invaded pathogens, as a large proportion of the listed genes were associated with AMPs and immune/ inflammatory responses (see Tables 2 and 4). GO enrichment analysis demonstrated that the pathways related to responding and killing microorganisms (interspecies interaction between organisms), leukocyte development and locomotion and regulation, and immune process were the top activated pathways, with enrichment scores of 11-22.

\section{Antimicrobial peptides}

The common genes in the comparisons clinical mastitis vs healthy cows and clinical vs subclinical mastitic cows contained at least 16 antimicrobial peptides, which all contributed to the top pathway "interspecies interaction between organisms" (enrichment score 22). These were $A Z U 1$, CAMP, CATHL1, CATHL2, CATHL4, CATHL5, CATHL6, CXCL13, DEFB1, DEFB10, DEFB4A, DEFB7, LCN2, PGLYRP1, PRTN3, PTX3, S1OOA8, S100A9, S100A12 and $L T F$. This suggests that upregulation of production of a variety of AMPs was related to the severity of the mammary inflammatory process and was one of main distinguishing differences in the way that circulating leukocytes responded to clinical mastitis compared with subclinical mastitis. This difference is likely to relate to the pathogen involved. E. coli infections have global effects which are generally of short duration and induce a rapid rise in the pro-inflammatory cytokines TNFA, IL1B and IL6 in mammary tissue via TLR4-dependent induced signalling [14, 39]. This results in a fast influx of neutrophils to inhibit bacterial growth. In contrast, gram-positive bacteria such as $S$. uberis cause a slower and less dramatic response [40] whereas S. aureus is associated with local and more persistent infections. In these cases TLR signalling increases IL6 expression but does not up-regulate TNFA and IL1B and so this pathogen is better able to evade the host immune response [39].

AMPs are key components of the innate immune system [41] in which leukocyte AMPs are multifunctional effector molecules [42]. They act as endogenous antibiotics to kill various pathogens directly by forming pores in their membranes via toroidal, carpet or barrel stave mechanisms. These pores allow cytoplasmic leakage that ultimately leads to cell death [43]. These antimicrobial activities were originally regarded as the primary functions of these peptides. It is now clear that, in addition to the direct activities, AMPs play important roles in regulating multiple aspects of innate and adaptive immunity, including inflammation and wound repair, and they are also involved in maintaining homeostasis [44, 45]. Over 2000 natural AMPs have been identified, of which cathelicidins and $\beta$-defensins are the most studied [45]. Members of both these families contribute to the first line of defence against many pathogens, including Grampositive and Gram-negative bacteria, viruses, fungi and some unicellular parasites [46, 47]. They both belong to a large group of cationic peptides with amphipathic properties, which enables them to permeate pathogen membranes [48]. At least seven cathelicidins and nine $\beta$-defensins have so far been identified in cattle [47, 49], and of these six cathelicidins and four $\beta$-defensins were identified in this study as being upregulated in leukocytes of cows with clinical mastitis. AMPs thus possess dual capacity to control infection directly and to regulate host defences to help clearance of 
the invaded pathogens. Conventional mastitis control strategies include antibiotic therapy but this raises major concerns over both antibiotic residues in milk and the increase in antimicrobial resistance [50]. The use of AMPs has, therefore, been proposed as an alternative to antibiotics and immunomodulators for treatment of several bacterial infections [43]. Synthetic cathelicidins with enhanced antimicrobial activity have now been engineered and may in future provide a novel treatment option for bovine mastitis [51].

\section{Metabolic effects}

In the present study, the downregulated genes in cows with both subclinical and clinical mastitis were associated with the biological functions related to homeostasis, such as localization, biological adhesion, developmental process and signalling. The leukocyte samples were taken in early lactation, around 14 days after calving. In peripartum cows, decreased feed intakes and increased energy demands to support lactation often result in negative energy balance [22]. Immune cells re-programme their cellular metabolism in response to bacterial and viral infections to provide energy and molecules for immune processes [52]. In cows developing an infection while also experiencing negative energy balance there is competition for limited nutrients between the demands of milk synthesis and mounting an immune response [53]. This leads to a decreased number and functionality of circulating immune cells [21, 54], which is likely to predispose cows to infections and inflammatory diseases, such as mastitis and endometritis [55]. In addition, metabolic hepatic pathways including those involving lipid metabolism are affected by mammary gland challenge with E. coli or $S$. aureus, demonstrating that the liver restricts metabolic tasks during a mammary infection [12]. The timing of the present study meant that the cows with subclinical or clinical mastitis were also likely to be experiencing a metabolic deficit, which may well have affected their immune responses.

\section{Study limitations}

This study was based on naturally occurring cases of mastitis in six herds of cows, in different countries and with differing genetics and management. This is both a strength of, and limitation to, the study. On the one hand, the variability between animals reduced the power of the analyses performed. On the other hand, the transnational approach to cow recruitment meant that the significant differences in gene expression which were detected are likely to be of more widespread relevance. We were, however, unable to measure protein expression in the leukocytes to confirm that the mRNA changes detected were reflected in protein production. It was also not possible within the study design to perform diagnostic tests to identify the pathogens involved and it is well known that different bacterial species cause different host responses [39, 56]. Despite this, similarities in response do still exist across bacterial species, and the upregulation of bacterial killing by AMPs and the downregulation of the biological functions related to homeostasis for the leukocytes are consistent with previous work. Another issue is that a number of major cytokines (IFNG, IL1B, IL6, IL8, IL10, IL12 and TNFA) are upregulated during mammary infections in a time dependent manner [40], but our study did not find their differential expression in the leukocytes. While their expression patterns can be well detected in cases of experimentally developed mastitis, we might have missed the peak expression values of these cytokines, as it was not possible to obtain samples at precise time points during the course of infection in naturally occurring cases.

\section{Conclusions}

The present study described the leukocyte transcriptome from cows with naturally occurring subclinical and clinical mastitis in early lactation using next generation sequencing and bioinformatics technology. To our knowledge, this is the first time that the transcriptomic profiles in cows with subclinical mastitis have been compared with those in both healthy cows and those with clinical mastitis. Both conditions were associated with significant changes in gene expression in circulating leukocytes in accordance with the severity of mammary inflammation. Cows with clinical mastitis had a greater number of upregulated genes involved in various immune processes including body defence, leucocyte migration and antigen presentation. These results using RNA-seq have validated previous work by showing greater upregulation of AMPs in cows with clinical compared with subclinical mastitis. This is consistent with the greater influx of activated neutrophils to the mammary gland experienced during clinical mastitis and is likely to increase their ability to kill invading pathogens. In the cases of subclinical mastitis many immune genes were also differentially expressed but to a lesser extent and there was a greater emphasis on metabolic pathways.

Supplementary Information The online version contains supplementary material available at https://doi.org/10.1007/s11033-021-06494-8.

Acknowledgements GplusE Consortium: Mark Crowe, Niamh McLoughlin, Alan Fahey, Elizabeth Matthews, Andreia Santoro, Colin Byrne, Pauline Rudd, Roisin O'Flaherty, Sinead Hallinan, Claire Wathes, Zhangrui Cheng, Ali Fouladi, Geoff Pollott, Dirk Werling, Beatriz Sanz Bernardo, Mazdak Salavati, Laura Buggiotti, Alistair Wylie, Matt Bell, Mieke Vaneetvelde, Kristof Hermans, Geert Opsomer, Sander Moerman, Jenne De Koster, Hannes Bogaert, Jan Vandepitte, Leila Vandevelde, Bonny Vanranst, Johanna Hoglund, Susanne Dahl, Klaus Ingvartsen, Martin Sørensen, Leslie Foldager, Soren Ostergaard, Janne Rothmann, Mogens Krogh, Else Meyer, 
Charlotte Gaillard, Jehan Ettema, Tine Rousing, Federica Signorelli, Francesco Napolitano, Bianca Moioli, Alessandra Crisa, Luca Buttazzoni, Jennifer McClure, Daragh Matthews, Francis Kearney, Andrew Cromie, Matt McClure, Shujun Zhang, Xing Chen, Huanchun Chen, Junlong Zhao, Liguo Yang, Guohua Hua, Chen Tan, Guiqiang Wang, Michel Bonneau, Andrea Pompozzi, Armin Pearn, Arnold Evertson, Linda Kosten, Anders Fogh, Thomas Andersen, Matthew Lucy, Chris Elsik, Gavin Conant, Jerry Taylor, Nicolas Gengler, Michel Georges, Frederic Colinet, Marilou Ramos Pamplona, Hedi Hammami, Catherine Bastin, Haruko Takeda, Aurelie Laine, Anne-Sophie Van Laere, Martin Schulze, Cinzia Marchitelli and Sergio Palma-Vera.

Funding This project received funding from the European Union's Seventh Framework Programme (Brussels, Belgium) for research, technological development, and demonstration under Grant Agreement No. 613689. The views expressed in this publication are the sole responsibility of the authors and do not necessarily reflect the views of the European Commission.

Data availability The sequencing data were deposited to the European Nucleotide Archive (ERP019874).

\section{Declarations}

Conflict of interest The authors declare that they have no conflict of interest.

Ethical standards All procedures had local ethical approval and complied with the relevant national and EU legislation under European Union Directive 2010/63/EU.

\section{References}

1. Oviedo-Boyso J, Valdez-Alarcon JJ, Cajero-Juarez M, OchoaZarzosa A, Lopez-Meza JE, Bravo-Patino A, Baizabal-Aguirre VM (2007) Innate immune response of bovine mammary gland to pathogenic bacteria responsible for mastitis. J Infect 54(4):399_ 409. https://doi.org/10.1016/j.jinf.2006.06.010

2. Ruegg PL (2017) A 100-year review: mastitis detection, management, and prevention. J Dairy Sci 100(12):10381-10397. https:// doi.org/10.3168/jds.2017-13023

3. Lawless N, Reinhardt TA, Bryan K, Baker M, Pesch B, Zimmerman D, Zuelke K, Sonstegard T, O'Farrelly C, Lippolis JD, Lynn DJ (2014) MicroRNA regulation of bovine monocyte inflammatory and metabolic networks in an in vivo infection model. G3 (Bethesda) 4(6):957-971. https://doi.org/10.1534/g3.113.009936

4. Wells SJ, Ott SL, Seitzinger AH (1998) Key health issues for dairy cattle-new and old. J Dairy Sci 81(11):3029-3035. https://doi.org/ 10.3168/jds.s0022-0302(98)75867-9

5. Bradley A (2002) Bovine mastitis: an evolving disease. Vet $\mathbf{J}$ 164(2):116-128. https://doi.org/10.1053/tvj1.2002.0724

6. Reinoso EB, Lasagno MC, Dieser SA, Odierno LM (2011) Distribution of virulence-associated genes in Streptococcus uberis isolated from bovine mastitis. FEMS Microbiol Lett 318(2):183-188. https://doi.org/10.1111/j.1574-6968.2011.02258.x

7. Ward PN, Holden MT, Leigh JA, Lennard N, Bignell A, Barron A, Clark L, Quail MA, Woodward J, Barrell BG, Egan SA, Field TR, Maskell D, Kehoe M, Dowson CG, Chanter N, Whatmore AM, Bentley SD, Parkhill J (2009) Evidence for niche adaptation in the genome of the bovine pathogen Streptococcus uberis. BMC Genomics 10:54. https://doi.org/10.1186/1471-2164-10-54
8. Pyorala S (2002) New strategies to prevent mastitis. Reprod Domest Anim 37(4):211-216. https://doi.org/10.1046/j.14390531.2002.00378.x

9. Leitner G, Yadlin B, Glickman A, Chaffer M, Saran A (2000) Systemic and local immune response of cows to intramammary infection with Staphylococcus aureus. Res Vet Sci 69(2):181-184. https://doi.org/10.1053/rvsc.2000.0409

10. Thompson-Crispi K, Atalla H, Miglior F, Mallard BA (2014) Bovine mastitis: frontiers in immunogenetics. Front Immunol 5:493. https://doi.org/10.3389/fimmu.2014.00493

11. Schukken YH, Wilson DJ, Welcome F, Garrison-Tikofsky L, Gonzalez RN (2003) Monitoring udder health and milk quality using somatic cell counts. Vet Res 34(5):579-596. https://doi.org/10. 1051/vetres:2003028

12. Heimes A, Brodhagen J, Weikard R, Seyfert HM, Becker D, Meyerholz MM, Petzl W, Zerbe H, Hoedemaker M, Rohmeier L, Schuberth HJ, Schmicke M, Engelmann S, Kuhn C (2020) Hepatic transcriptome analysis identifies divergent pathogenspecific targeting-strategies to modulate the innate immune system in response to intramammary infection. Front Immunol 11:715. https://doi.org/10.3389/fimmu.2020.00715

13. Jiang L, Sorensen P, Rontved C, Vels L, Ingvartsen KL (2008) Gene expression profiling of liver from dairy cows treated intramammary with lipopolysaccharide. BMC Genomics 9:443. https://doi.org/10.1186/1471-2164-9-443

14. Moyes KM, Sorensen P, Bionaz M (2016) The Impact of intramammary Escherichia coli challenge on liver and mammary transcriptome and cross-talk in dairy cows during early lactation using RNAseq. PLoS One 11(6):e0157480. https://doi.org/10. 1371/journal.pone.0157480

15. Rinaldi M, Li RW, Capuco AV (2010) Mastitis associated transcriptomic disruptions in cattle. Vet Immunol Immunopathol 138(4):267-279. https://doi.org/10.1016/j.vetimm.2010.10.005

16. Chen X, Cheng Z, Zhang S, Werling D, Wathes DC (2015) Combining genome wide association studies and differential gene expression data analyses identifies candidate genes affecting mastitis caused by two different pathogens in the dairy cow. Open J Anim Sci 05(04):358-393. https://doi.org/10.4236/ojas.2015. 54040

17. Bruckmaier RM, Wellnitz O (2017) TRIENNIAL LACTATION SYMPOSIUM/BOLFA: pathogen-specific immune response and changes in the blood-milk barrier of the bovine mammary gland. J Anim Sci 95(12):5720-5728. https://doi.org/10.2527/jas2017. 1845

18. Sheldon IM, Lewis GS, LeBlanc S, Gilbert RO (2006) Defining postpartum uterine disease in cattle. Theriogenology 65(8):15161530. https://doi.org/10.1016/j.theriogenology.2005.08.021

19. Vangroenweghe F, Lamote I, Burvenich C (2005) Physiology of the periparturient period and its relation to severity of clinical mastitis. Domest Anim Endocrinol 29(2):283-293. https://doi.org/ 10.1016/j.domaniend.2005.02.016

20. Mallard BA, Dekkers JC, Ireland MJ, Leslie KE, Sharif S, Vankampen CL, Wagter L, Wilkie BN (1998) Alteration in immune responsiveness during the peripartum period and its ramification on dairy cow and calf health. J Dairy Sci 81(2):585-595. https://doi.org/10.3168/jds.s0022-0302(98)75612-7

21. Wathes DC, Cheng Z, Chowdhury W, Fenwick MA, Fitzpatrick R, Morris DG, Patton J, Murphy JJ (2009) Negative energy balance alters global gene expression and immune responses in the uterus of postpartum dairy cows. Physiol Genomics 39(1):1-13. https:// doi.org/10.1152/physiolgenomics.00064.2009

22. Ingvartsen KL, Moyes K (2013) Nutrition, immune function and health of dairy cattle. Animal 7(Suppl 1):112-122. https://doi.org/ 10.1017/S175173111200170X

23. Ster C, Loiselle MC, Lacasse P (2012) Effect of postcalving serum nonesterified fatty acids concentration on the functionality 
of bovine immune cells. J Dairy Sci 95(2):708-717. https://doi. org/10.3168/jds.2011-4695

24. Kehrli ME Jr, Shuster DE (1994) Factors affecting milk somatic cells and their role in health of the bovine mammary gland. J Dairy Sci 77(2):619-627. https://doi.org/10.3168/jds.S00220302(94)76992-7

25. Lacetera N, Scalia D, Bernabucci U, Ronchi B, Pirazzi D, Nardone A (2005) Lymphocyte functions in overconditioned cows around parturition. J Dairy Sci 88(6):2010-2016. https://doi.org/10.3168/ jds.S0022-0302(05)72877-0

26. Nonnecke BJ, Kimura K, Goff JP, Kehrli ME Jr (2003) Effects of the mammary gland on functional capacities of blood mononuclear leukocyte populations from periparturient cows. J Dairy Sci 86(7):2359-2368. https://doi.org/10.3168/jds.S0022-0302(03) 73829-6

27. Mitterhuemer S, Petzl W, Krebs S, Mehne D, Klanner A, Wolf E, Zerbe H, Blum H (2010) Escherichia coli infection induces distinct local and systemic transcriptome responses in the mammary gland. BMC Genomics 11:138. https://doi.org/10.1186/ 1471-2164-11-138

28. Petzl W, Zerbe H, Gunther J, Seyfert HM, Hussen J, Schuberth HJ (2018) Pathogen-specific responses in the bovine udder. Models and immunoprophylactic concepts. Res Vet Sci 116:55-61. https://doi.org/10.1016/j.rvsc.2017.12.012

29. De Koster J, Salavati M, Grelet C, Crowe MA, Matthews E, O'Flaherty R, Opsomer G, Foldager L, GplusE HM (2019) Prediction of metabolic clusters in early-lactation dairy cows using models based on milk biomarkers. J Dairy Sci 102(3):2631-2644. https://doi.org/10.3168/jds.2018-15533

30. Krogh MA, Hostens M, Salavati M, Grelet C, Sorensen MT, Wathes DC, Ferris CP, Marchitelli C, Signorelli F, Napolitano F, Becker F, Larsen T, Matthews E, Carter F, Vanlierde A, Opsomer G, Gengler N, Dehareng F, Crowe MA, Ingvartsen KL, Foldager L (2020) Between- and within-herd variation in blood and milk biomarkers in Holstein cows in early lactation. Animal 14(5):10671075. https://doi.org/10.1017/S1751731119002659

31. Larsen T, Rontved CM, Ingvartsen KL, Vels L, Bjerring M (2010) Enzyme activity and acute phase proteins in milk utilized as indicators of acute clinical E. coli LPS-induced mastitis. Animal 4(10):1672-1679. https://doi.org/10.1017/S1751731110000947

32. Green MJ, Bradley AJ, Medley GF, Browne WJ (2007) Cow, farm, and management factors during the dry period that determine the rate of clinical mastitis after calving. J Dairy Sci 90(8):37643776. https://doi.org/10.3168/jds.2007-0107

33. Steeneveld W, Hogeveen H, Barkema HW, van den Broek J, Huirne RB (2008) The influence of cow factors on the incidence of clinical mastitis in dairy cows. J Dairy Sci 91(4):1391-1402. https://doi.org/10.3168/jds.2007-0705

34. Luoreng ZM, Wang XP, Mei CG, Zan LS (2018) Expression profiling of peripheral blood miRNA using RNAseq technology in dairy cows with Escherichia coli-induced mastitis. Sci Rep 8(1):12693. https://doi.org/10.1038/s41598-018-30518-2

35. Wang D, Liu L, Augustino SMA, Duan T, Hall TJ, MacHugh DE, Dou J, Zhang Y, Wang Y, Yu Y (2020) Identification of novel molecular markers of mastitis caused by Staphylococcus aureus using gene expression profiling in two consecutive generations of Chinese Holstein dairy cattle. J Anim Sci Biotechnol 11:98. https://doi.org/10.1186/s40104-020-00494-7

36. Yalcin C, Stott AW, Logue DN, Gunn J (1999) The economic impact of mastitis-control procedures used in Scottish dairy herds with high bulk-tank somatic-cell counts. Prev Vet Med 41(23):135-149. https://doi.org/10.1016/s0167-5877(99)00052-5

37. Berry MP, Graham CM, McNab FW, Xu Z, Bloch SA, Oni T, Wilkinson KA, Banchereau R, Skinner J, Wilkinson RJ, Quinn C, Blankenship D, Dhawan R, Cush JJ, Mejias A, Ramilo O, Kon OM, Pascual V, Banchereau J, Chaussabel D,
O'Garra A (2010) An interferon-inducible neutrophil-driven blood transcriptional signature in human tuberculosis. Nature 466(7309):973-977. https://doi.org/10.1038/nature09247

38. Blankley S, Berry MP, Graham CM, Bloom CI, Lipman M, O'Garra A (2014) The application of transcriptional blood signatures to enhance our understanding of the host response to infection: the example of tuberculosis. Philos Trans R Soc Lond B Biol Sci 369(1645):20130427. https://doi.org/10.1098/rstb. 2013.0427

39. Schukken YH, Gunther J, Fitzpatrick J, Fontaine MC, Goetze L, Holst O, Leigh J, Petzl W, Schuberth HJ, Sipka A, Smith DG, Quesnell R, Watts J, Yancey R, Zerbe H, Gurjar A, Zadoks RN, Seyfert HM, members of the Pfizer mastitis research c (2011) Host-response patterns of intramammary infections in dairy cows. Vet Immunol Immunopathol 144(3-4):270-289. https://doi.org/ 10.1016/j.vetimm.2011.08.022

40. Bannerman DD (2009) Pathogen-dependent induction of cytokines and other soluble inflammatory mediators during intramammary infection of dairy cows. J Anim Sci 87(13 Suppl):10-25. https://doi.org/10.2527/jas.2008-1187

41. Pasupuleti M, Schmidtchen A, Malmsten M (2012) Antimicrobial peptides: key components of the innate immune system. Crit Rev Biotechnol 32(2):143-171. https://doi.org/10.3109/07388551. 2011.594423

42. Risso A (2000) Leukocyte antimicrobial peptides: multifunctional effector molecules of innate immunity. J Leukoc Biol 68(6):785-792

43. Afacan NJ, Yeung AT, Pena OM, Hancock RE (2012) Therapeutic potential of host defense peptides in antibiotic-resistant infections. Curr Pharm Des 18(6):807-819. https://doi.org/10.2174/13816 1212799277617

44. Auvynet C, Rosenstein Y (2009) Multifunctional host defense peptides: antimicrobial peptides, the small yet big players in innate and adaptive immunity. FEBS J 276(22):6497-6508. https://doi. org/10.1111/j.1742-4658.2009.07360.x

45. Hilchie AL, Wuerth K, Hancock RE (2013) Immune modulation by multifaceted cationic host defense (antimicrobial) peptides. Nat Chem Biol 9(12):761-768. https://doi.org/10.1038/nchembio. 1393

46. Brogden KA (2005) Antimicrobial peptides: pore formers or metabolic inhibitors in bacteria? Nat Rev Microbiol 3(3):238-250. https://doi.org/10.1038/nrmicro1098

47. Kosciuczuk EM, Lisowski P, Jarczak J, Strzalkowska N, Jozwik A, Horbanczuk J, Krzyzewski J, Zwierzchowski L, Bagnicka E (2012) Cathelicidins: family of antimicrobial peptides. A review. Mol Biol Rep 39(12):10957-10970. https://doi.org/10.1007/ s11033-012-1997-x

48. Andreu D, Rivas L (1998) Animal antimicrobial peptides: an overview. Biopolymers 47(6):415-433. https://doi.org/10.1002/(SICI) 1097-0282(1998)47:6\%3c415::AID-BIP2\%3e3.0.CO;2-D

49. Gurao A, Kashyap SK, Singh R (2017) beta-defensins: an innate defense for bovine mastitis. Vet World 10(8):990-998. https://doi. org/10.14202/vetworld.2017.990-998

50. Stanton TB (2013) A call for antibiotic alternatives research. Trends Microbiol 21(3):111-113. https://doi.org/10.1016/j.tim. 2012.11.002

51. Young-Speirs M, Drouin D, Cavalcante PA, Barkema HW, Cobo ER (2018) Host defense cathelicidins in cattle: types, production, bioactive functions and potential therapeutic and diagnostic applications. Int J Antimicrob Agents 51(6):813-821. https://doi. org/10.1016/j.ijantimicag.2018.02.006

52. Loftus RM, Finlay DK (2016) Immunometabolism: cellular metabolism turns immune regulator. J Biol Chem 291(1):1-10. https://doi.org/10.1074/jbc.R115.693903

53. Habel J, Sundrum A (2020) Mismatch of glucose allocation between different life functions in the transition period of dairy 
cows. Animals (Basel) 10(6):1028-1049. https://doi.org/10.3390/ ani 10061028

54. LeBlanc SJ (2012) Interactions of metabolism, inflammation, and reproductive tract health in the postpartum period in dairy cattle. Reprod Domest Anim 47(Suppl 5):18-30. https://doi.org/10. 1111/j.1439-0531.2012.02109.x

55. Moyes KM, Larsen T, Ingvartsen KL (2013) Generation of an index for physiological imbalance and its use as a predictor of primary disease in dairy cows during early lactation. J Dairy Sci 96(4):2161-2170. https://doi.org/10.3168/jds.2012-5646
56. Bradley AJ, Leach KA, Breen JE, Green LE, Green MJ (2007) Survey of the incidence and aetiology of mastitis on dairy farms in England and Wales. Vet Rec 160(8):253-257. https://doi.org/ $10.1136 /$ vr.160.8.253

Publisher's Note Springer Nature remains neutral with regard to jurisdictional claims in published maps and institutional affiliations. 